\title{
ALFONSO DE GRANA Y LA RESTAURACIÓN DE LA COLECCIÓN REAL DE ESCULTURA EN EL SIGLO XVIII
}

\author{
POR \\ MARÍA LUISA TÁRRAGA BALDÓ \\ C.S.I.C.
}

\begin{abstract}
El tema de la restauración de la Colección Real de Esculturas llevada a cabo tras el incendio del Alcázar carece de antecedentes bibliográficos. En el presente artículo se pone de manifiesto cómo la alta estima de la monarquía por sus colecciones artísticas y la actuación de los escultores a su servicio han jugado un papel destacado en la conservación y restauración de este Patrimonio. Se examinan las primeras intervenciones emprendidas por el escultor Alfonso de Grana, desvelándonos algunas de las piezas restauradas y los criterios de restauración que practica, enfrentados con los de los escultores Felipe de Castro y Olivieri.
\end{abstract}

Palabras clave: Escultura. S. XviII. Restauración. Alfonso de Grana.

The theme of the restoration of the Royal Sculpture Collection carried out following the fire in the Madrid Alcázar is totally lacking in bibliographic antecedents. In this article the author demonstrates how the high esteem in which the Spanish Monarchy held its collections and the interventions of the sculptors in its service played an outstanding role in the conservation and restoration of this Patrimony. The first efforts undertaken by the sculptor Alfonso de Grana, some of the pieces restored by him and his criteria for restoration are examined and confronted with those of the sculptors Felipe de Castro and Olivieri.

Key words: Sculpture. XVIII Century. Restoration. Alfonso de Grana.

El tema de la restauración de la colección real de esculturas llevada a cabo en el siglo XviII, en la corte española, carece de antecedentes bibliográficos; en parte, por la escasa tradición investigadora que en materia de conservación y restauración ha tenido nuestro país. El interés, podemos decir que, es relativamente reciente y ha venido fomentado por la política científica desarrollada tanto por la Comunidad Europea como por nuestros Planes Nacionales de I+D, así como por los Planes Regionales de la Comunidad de Madrid y otras Comunidades Autónomas.

Aun reconociendo la falta de bibliografía específica sobre el tema, disponemos de referencias documentales que manifiestan la preocupación constante por la conservación de este Patrimonio y los criterios que sobre la restauración escultórica ha tenido la monarquía, algunos de nuestros artistas y, posteriormente, algunos responsables y directores de nuestra primera pinacoteca. Es el caso concreto de José y Federico de Madrazo, quienes han dejado en su correspondencia con la Casa Real o en breves escritos, algunos de ellos inéditos, verdaderas formulaciones al respecto, que sirven, al menos, como testimonio de su interés por la conserva- 
ción de este Patrimonio, a la vez que sus opiniones y criterios suponen una nada desdeñable aportación sobre el tema. A ello hay que añadir el discurso leído ante la Academia de Bellas Artes de San Fernando por Eduardo Barrón, en su recepción pública, el 11 de diciembre de $1910^{~}$. En el caso de Barrón su preocupación le llevó a que años más tarde, al elaborar el Catálogo de la Escultura del Museo del Prado, dejase constancia, en cada pieza, de las restauraciones que las mismas presentaban.

Dentro de esta reseña bibliográfica no podemos olvidar a E. Tormo, quien en 1944 en su obra «El Catálogo de las Esculturas. La Sala de las Musas» señala las restauraciones de las ocho Musas pertenecientes a la colección de Cristina de Suecia e incluso el material empleado para llevarlas a cabo,dando referencias y plantillas que expresan de forma gráfica la intervención de los restauradores en las referidas obras, y citando como restauradores a los escultores italianos Bernini, Hercole Ferrata,Nocchieri, Rusconi, Soldano Benzi y nuestro toledano Valeriano Salvatierra. En esta misma línea ha continuado Stefan Schröeder al publicar el Catálogo de la escultura clásica del Museo.

Me parece oportuno, asimismo,añadir el trabajo que en 1994, con motivo de la exposición celebrada en el Museo del Prado sobre «Los Leoni, escultores del Renacimiento en la Corte Española» di a conocer en el Catálogo de la misma ${ }^{2}$. Estudio dedicado a las intervenciones a que se había sometido la obra de estos artistas, hoy conservadas en el Prado y, que como tal, forman parte de la Colección Real.

En el caso de la investigación que nos ocupa, centrado en el siglo xviII, careciendo de bibliografía sobre el tema, han sido los archivos la más valiosa y directa fuente de información.

Como es sabido, la restauración se propone reparar los daños que se han producido, pero de acuerdo con los criterios que se adopten en la intervención los fragmentos rotos pueden ser ocultados, pueden unirse o ser reemplazados. En general, la restauración es una actividad que suele suscitar problemas y criterios encontrados, si bien, al margen de los criterios asumidos, el objeto restaurado, tras la intervención, generalmente se suele salvar, aunque deje de ser menos original.

Recientemente encontré un documento bastante curioso al respecto. El documento hace referencia a la «centella» que, con motivo de una tempestad acaecida en 1711, había penetrado en el interior de la Real Capilla del Alcázar madrileño, causando una serie de desperfectos. El rey Felipe V se interesó por lo sucedido y pidió a su arquitecto Teodoro Ardemans que le informase de todos los destrozos que había producido. En el informe, entre otros detalles, se especifica que «desbarató un lienzo de los Niños pintados por Jordán en la Real Capilla, situado en los vaciados de las pilastras de dho toral y echamuscó en dos o tres partes unas fajas doradas y las colgaduras contiguas...». Felipe $\mathrm{V}$, tras conocer el informe, ordenó, y transcribo textualmente: «Se repare...sin llegar a la pintura, que puede padecer mas en el remedio». Sin embargo, en el siglo xviII se quiso remediar el deterioro que la colección real de esculturas presentaba.

Partiendo de las diversas causas que han contribuido al deterioro de la colección, y a través de datos documentales de archivos, así como con la ayuda de Testamentarías Reales, Inventarios y Catálogos de Escultura, como principal fuente bibliográfica, hemos logrado conocer cómo, quiénes y con qué criterios se procedió a la restauración de esta colección en el referido siglo y, concretamente, quiénes fueron los responsables de salvar este patrimonio escultórico. La abundante burocracia de la Corte y de un siglo como el que nos ocupa han dejado suficientes testimonios en este sentido. Los artistas estaban obligados a firmar imnumera-

1 E. Barrón; Conservación de las Esculturas Antiguas. Discursos leídos ante la Real Academia de Bellas Artes de San Fernando en la recepción pública del Ilmo. Sr.D. Eduardo Barrón el 11 de diciembre de 1910. Madrid, 1910 , pp. 5-18.

${ }^{2} \mathrm{M}^{\mathrm{a}}{ }^{\mathrm{L}}$ Luisa Tárraga Baldó, «Investigaciones sobre las restauraciones históricas de la obra de los Leoni conservadas en el Museo del Prado» en: Los Leoni (1509-1608). Museo del Prado, 1994, pp. 87-99.

$A E A$, LXXVII, 2004, 305, pp. 21 a 33 
bles justificantes a los responsables de custodiar las piezas, tanto cuando éstos se las entregaban como cuando los escultores, una vez compuestas, las depositaban en Palacio.El haber logrado identificar quiénes fueron los escultores responsables de practicar las intervenciones y algunos otras noticias, como la opinión que la restauración que se practicó inicialmente merecieron a escultores como Felipe de Castro u Olivieri, nos ha permitido vislumbrar algunos de los criterios que en materia de restauración prevalecieron en el siglo xvIII e incluso la opinión personal del escultor Felipe de Castro.

Si bien la utilización de los los Inventarios Reales han sido una ayuda imprescindible para la investigación en este campo, sin embargo,no dejan de presentar serios inconvenientes, dado lo parcos que suelen ser en cuanto a referencias o descripción de las piezas de escultura. Este hecho ya fue señalado por Sánchez Cantón, cuando llevó a cabo la inmensa y provechosa tarea de transcribir algunos de ellos. El prestigioso historiador detalla con minuciosidad qué cuadros son los que faltan con respecto a inventarios precedentes en la colección real, o cuáles los que se incrementan en un determinado reinado, pero él mismo nos confiesa en uno de sus trabajos la imposibilidad de adoptar un criterio similar con respecto a la colección de esculturas, por lo que renuncia a recogerlas, ante la imposibilidad de su identificación, teniendo en cuenta la forma en la que las piezas aparecen descritas.El hecho se suele repetir casi en la mayoría de los inventarios hallados.

También es preciso señalar que, a pesar de la valoración que desde hace algún tiempo ha adquirido el arte cortesano del xvIII, las investigaciones se han volcado preferentemente sobre la pintura o la arquitectura y, en menor medida, sobre la escultura.

En la conservación de la colección de escultura partimos evidentemente de un hecho y es la alta estima en que nuestros monarcas tenían sus colecciones artísticas, y que ha sido clave para preservar este importante Patrimonio, propiciando, en gran medida, el que a pesar de haberse producido circunstancias adversas, como sin duda lo fue, entre otras, el incendio del Alcázar madrileño, acaecido casi al mediar el siglo xvIII, una buena parte de esta colección haya podido llegar hasta nosotros.

Pero en la conservación de la colección real de escultura, junto al concepto patrimonial del arte de nuestros monarcas, jugó un papel destacado el interés y el parecer de determinados artistas al servicio de los reyes y, principalmente, los escultores de cámara. A ellos se unirá, posteriormente, tal y como he tenido ocasión de comprobar, la figura del pintor Antonio Rafael Mengs. Todos ellos, en general, unas veces movidos por el deseo de remediar una situación personal, y sobre todo, por el afán de salvar las obras maestras que guardaban los Palacios Reales, lograron garantizar la conservación de una gran parte de este Patrimonio hasta nuestros días.

Como factores que habían contribuido al deterioro de las piezas se pueden señalar varias causas, pero hay que reconocer que, desgraciadamente, suelen ser escasas las obras de arte que escapan a los estragos ocasionados por dos factores fundamentales: hombre y tiempo. A ello, en el caso de esta colección, se suman otras circunstancias particulares y concretas como: el deambular a que se habían visto sometidas una parte importante de las obras, bien por su procedencia italiana, como sucede con la colección de la Reina Cristina de Suecia, con todos los problemas que el traslado y un largo viaje implica. En este ir de acá para allá no son menos ajenos los gustos cambiantes de la monarquía y el cambio de dinastía, que obliga a trasladar estatuas que, en más de una ocasión, van y vienen, a pesar de las dificultades que implica el propio material de que están hechas: mármol, con su consiguientemente peso, y los medios técnicos con que se cuenta para su transporte, pero que, complaciendo el gusto real, se mueven entre los distintos Palacios o Sitios Reales: Buen Retiro, Aranjuez, Madrid, La Graja de San Ildefonso, sin reparar en dificultades. 
Otro factor a tener en cuenta es el almacenamiento de las obras en no muy buenas condiciones. Ejemplo claro y conocido en este sentido es el de una parte de la obra de Los Leoni, que permanecieron almacenadas durante gran número de años, según lo corroboran los dos inventarios frecuentemente citados de 1582 y 1.608. Sucede, además, que dada la cantidad de piezas acumuladas, no era posible que todas permaneciesen expuestas y su almacenamiento era obligado en previsión de algún destino posterior.

Igualmente, contribuyó a su mal estado la permanencia a la intemperie, ornamentando fachadas, plazas y jardines. En este caso, los agentes climatológicos o atmosféricos son los que han dejando, con el paso del tiempo, su huella en ellas.

En definitiva, aun aquellas que estuvieron expuestas en el interior de los edificios, tampoco podemos decir que gozasen de las condiciones ambientales más idóneas, al menos, tal y como hoy se conciben. Pero, a pesar de todo lo expuesto, la causa principal de sus desperfectos y el que mayores repercusiones tuvo sobre la colección fue, sin duda, el incendio que sufrió el Alcázar en 1734, puesto que no sólo supuso importantes pérdidas, sino destrozos en las obras, en algunos casos irreparables.

Pocas o ninguna referencia, como ya he advertido, se han hecho hasta ahora de la repercusión del incendio sobre la colección de esculturas, tanto en madera, bronce, como mármol, barro, pórfido o márfil. Se nos han facilitado datos de los daños con respecto a la pintura, pero nada apenas se conoce de la escultura.

La noticias de archivo encontradas, en este sentido, son varias y ellas nos desvelan, entre otras, que hubo necesidad inmediata de constatar, cotejando diferentes inventarios, las pérdidas ocasionadas por el incendio sobre este patrimonio real; conocer cúales habían sido las obras desaparecidas y cúales las dañadas. De forma que, aparte de acudir a los inventarios de 1686 , y al de Carlos II, al escultor Alfonso de Grana, que había estado encargado de tasar la colección a la muerte de Felipe $\mathrm{V}^{3}$, se le encargó inventariase esta parte de la colección nuevamente, estableciendo una nueva valoración que pone de manifiesto diferencias apreciables no sólo en número de piezas, sino en las cifras de valoración. Porque, como aclara el mismo documento «... en el Incendio de 1734 se quemaron muchas, y se maltrataron e inutilizaron otras perdiendo su principal estimación; pues las más se arrojaron por las ventanas a la Plazuela; en cuya forma fue grande el daño que recibieron, especialmente las estatuas, urnas, y otras especies de Alajas, por lo esquisito de su materia: y habiéndose tasado en el Inventario último su valor actual, es consiguiente sea mucho menos que el se le considero por muerte de Sr. Carlos segundo, teniendo presente también el uso de cuarenta y seis años...» ${ }^{4}$.

Se añadió a los daños del incendio el producido por tener que ser almacenadas posteriormente, como así lo corrobora otro documento fechado el 18 de febrero de 1737 y firmado por el arquitecto Saqueti,dirigido al Marqués de Villarias, en donde pedía de forma apremiante «un lugar donde almacenar Estatuas Columnas, Jaspes, Adornos de chimenea y otras cosas semejantes, que se iran quitando en la demolición del Palacio Viejo ... será menester ... facilite las llaves de aquellos Sótanos u Bobedas, que antecedentemente sirvieron a los oficios de Boca de S.M. y otras casas que son de su dependencia ... y que la orden venga sin dilación porque hacen suma falta dichos sótanos...» ${ }^{5}$. El 19 de febrero el Rey ordenaba que el Intendente Manuel de Miranda entregase las llaves de todos los sótanos y de todos aquellos lugares que sirviesen para almacenar estatuas. Uno de los lugares elegidos entonces para guardarlas, sabemos que fueron las Casas Arzobispales.

3 Archivo General del Palacio (A.G.P) Sec. Personal C. ${ }^{\text {a }} 477 / 39$.

${ }^{4}$ A.G.P. Sec. Reinado de Fernando VI C. ${ }^{\text {a }} 319 / 4$

5 A.G.P. Sec. Ob. Leg. ${ }^{\circ} 453$.

AEA, LXXVII, 2004, 305, pp. 21 a 33 

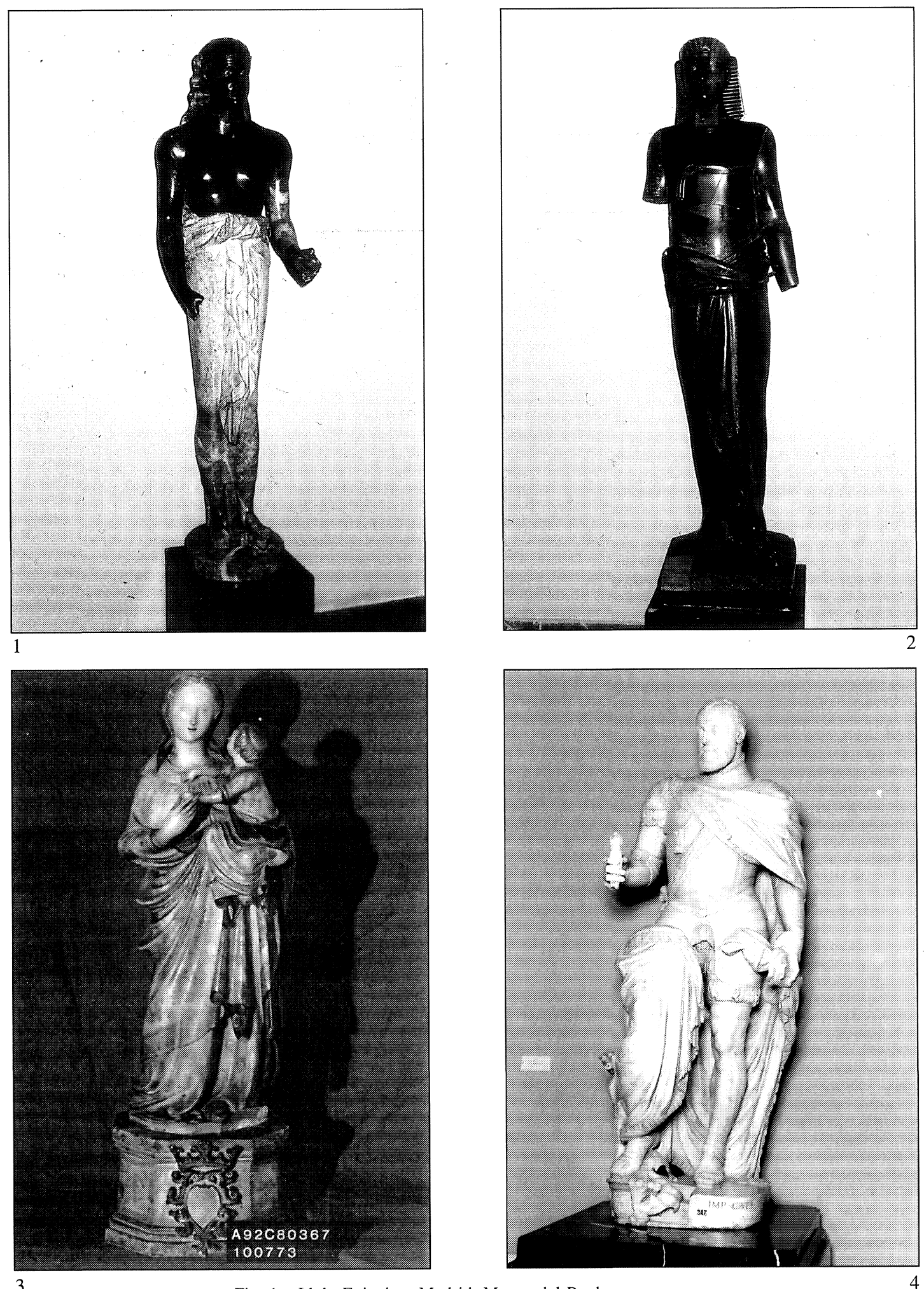

3

Fig. 1. «Idolo Egipcio». Madrid. Museo del Prado.

Fig. 2. «Idolo Egipcio». Madrid. Museo del Prado.

Fig. 3. Anónimo. Ntra. Sra. de Trapani. Madrid. Palacio Real.

Fig. 4. Los Leoni: Carlos V. Madrid. Museo del Prado.

AEA, LXXVII, 2004, 305, pp. 21 a 33 
Reunidas allí, al igual que se procedió a restaurar las pinturas, era lógico que se plantease el llevar a cabo una labor similar para recuperar las estatuas. Pero en este caso la decisión se produjo con cierto retraso con respecto a la restauración pictórica, sin duda porque había necesidades más apremiantes a las que atender y todos los esfuerzos personales, artísticos y económicos están concentrados en la reedificación del nuevo Palacio. Tampoco urgía su recuperación, ya que no estaba previsto un destino inmediato para ellas.

Previamente a estos acontecimientos, conviene señalar que, en el primer tercio del siglo, Felipe V y, especialmente, su esposa Isabel de Farnesio se erigieron en pioneros de la restauración escultórica en la España del xviII, puesto que contrataron a su servicio, en 1726, en la Granja de San Ildefonso, a un escultor italiano, concretamente florentino, que había trabajado en la Corte de Turín: Gasparo Petri, al parecer, con el único y exclusivo fin de componer las estatuas de mármol de la Colección de la Reina Cristina de Suecia ${ }^{6}$. Era lógico que, dado el interés de ambos reyes por poseer esta colección, una vez que llegó a la Granja y fue desembalada, quisieron que algún experto se encargase de reparar los posibles desperfectos ocasionados por el viaje no sólo entre Alicante y Segovia, sino también los que se produjeron en su traslado desde Italia a Alicante. Estos desperfectos se ponen de manifiesto al llegar a España y hacerse cargo de ellas el carretero que las trasladará hasta La Granja. Las obras, previamente a emprender el camino, han de pesarse para su pago al transportista y, a la vez, para conocer el estado en que éste las recibe; por ello se abrieron los cajones en Alicante. De forma pormenorizada la documentación hallada especifica cuáles han llegado con los dedos rotos, la mano o el muslo destrozado, la cabeza separada o cualquier otra parte del cuerpo fracturado, aclarando si la rotura es de «fresco» o de «antiguo». El inconveniente que presenta esta puntual relación es que quienes la hicieron carecen de los conocimientos precisos para transmitirnos una información que tenga en cuenta la iconografía de la estatua y nos facilite así su identificación. Por supuesto, aún menos los carreteros, porque aparte de saber el daño que presentan algunas estatuas, lo esencial para ellos era conocer con precisión el número de arrobas que tenían las piezas que debían transportar.

Algunos años después y, tras haber permanecido el escultor Gasparo Petri algún tiempo en su país, este mismo artífice regresó nuevamente a España y en esta ocasión nos consta que trabajó también en la Granja, pero no colaborando en labrar las esculturas de sus jardines, sino en la recuperación de los llamados «idolos egipcios»obras pertenecientes a la colección del Marqués del Carpio y que habían sido adquiridos por los Reyes Felipe V e Isabel de Farnesio, algunos de ellos hoy en el Museo del Prado (figs. 1 y 2). Estas estatuas habían sido ya sometidas a una pesada restauración en Roma, cuando pertenecieron al Cardenal Massimi, porque algunas carecían de brazos e incluso de la base. Testimonio de su existencia en La Granja son los dibujos del Abate Ajello, que tienen una correspondencia casi perfecta con el álbum de la colección del Carpio conservado en Londres. Los cambios que presentan estas estatuas respecto a estos dibujos, tanto en la posición de las manos como en el tocado, atributos, trajes, etc., pueden atribuirse, precisamente, a aquellos cambios introducidos por la restauración. Hoy, estos ídolos los contemplamos, algunos sin brazos y otros sin extremedidades. Esta nueva imagen puede obedecer, sin duda, a otros criterios posteriores sobre restauración y conservación de la escultura.

Al acaecer el incendio del Alcázar bajo el reinado de Felipe V, parece igualmente lógico pensar que procediesen de forma similar y les preocupase la recuperación inmediata de una colección que habíase formado a lo largo de tres siglos. Sin embargo, la iniciativa no corres-

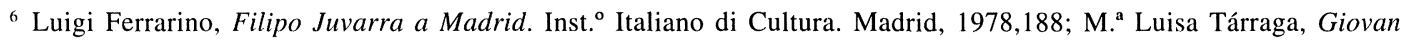
Domenico Olivieri y el Taller de Escultura del Palacio Real. Vol. II, pp. 140-143.
}

$A E A$, LXXVII, 2004, 305, pp. 21 a 33 
pondió a Felipe V, ni a Carlos III, a quien normalmente se viene señalando como el impulsor de esta recuperación. Sin que pretendamos restar importancia a la labor que en este aspecto desarrolló Carlos III, hoy estamos en condiciones de afirmar que la restauración de la colección, inicialmente, se debió a Fernando VI. En este sentido es interesante constatar que justamente fue durante su gobierno, cuando también se nombró en el Real Sitio de Aranjuez un escultor destinado concretamente «para la restauración de las Estatuas de los Jardines de Aranjuez», cargo que ostentarían el escultor Manuel Adeba Pacheco y el murciano Juan Bautista Martínez Reyna.

La iniciativa de restaurar la colección de esculturas partió, en principio, del escultor vallisoletano Alfonso de Grana, artista cuya identificación di a conocer en un estudio dedicado al Prof. Martín González ${ }^{7}$.

Alfonso de Grana, por su especial habilidad, había sido nombrado por el marqués de Santa Cruz escultor de Cámara de la reina Isabel de Farnesio, el 5 de julio de 1733 y el 13 de septiembre de 1746 fue nombrado escultor de cámara honorario de Fernando VI ${ }^{8}$. Se había encargado de realizar el inventario de la escultura en la testamentaría de la reina Mariana de Noeburgo y Felipe V, así como el efectuado tras el incendio. Todo ello le permitía conocer con detalle el estado de la colección. Grana dirige, pues, una instancia al monarca Fernando VI fechada en agosto de 1746, en el que textualmente le dice que «deseando sacrificar su Persona y habilidad en servicio de V.M. y habiendo quedado maltratadas en el Yncendio del Rl Palacio, muchas Estatuas de Madera, Piedra, Bronze, Marfil y Barro, assi de Santos, como de toda suertte pertenezientes a su Artte, que exerce, si sin satisfaccion propia, a la de todos los Gefes de la Rl Cassa de V.M.... y en atención a hallarse actualmente componiendo las Pinturas que también quedaron maltratadas en el referido Yncendio con Rl. Nombramiento y competente sueldo el pintor de Camara Juan de Miranda, Supplc. ${ }^{a}$ a V.M. que continuandole su Rl honra, se digne nombrarle para la composicion de las referidas Estatuas, según que como lleva expuesto, esta practicando la misma obra con las Pinturas, qe quedaron igualmente destruidas Dn Juan de Miranda... señalandole el sueldo que V.M. tubiere a bien considerarle proporcionado álas muchas estatuas que se necesitan componer; ó en su defectto y por no recargar por de contado el Rl Errario, que se le mande poner luego por obra la ejecucion de la composicion de las Estatuas, y concluida que sea, se le dé la remuneracion que pareciere a la Justificacion de V.M. pues se lisongea la desempeñará mediante el vigilantte cuydado, y aciertto qe confia acreditaran los Ynformes del Mayordomo m. ${ }^{\circ} r$ Duque de la Mirandola...» ${ }^{9}$. Pone, pues, en consideración del monarca que es propio que prefiera para confiar estos encargos a los criados de S.M., pues era costumbre, hasta entonces, que cuantos servicios en arte precisasen los reyes siempre habían sido los encargados los maestros y artífices de Cámara. Grana, quizás consciente de las dificultades económicas del erario regio, sugiere en su propuesta, para que no supusiese una carga a las arcas reales, que él procedería a ejecutar la composición de las estatuas, y sólo una vez concluidas se le concediese la remuneración que pareciese a S.M.

Alfonso de Grana consiguió convencer con su propuesta al monarca Fernando VI, quien, por real decreto de 11 de septiembre de 1746, accedía a su solicitud de forma inmediata a través del marqués de Villarias y previo informe del Duque de la Mirandola ${ }^{10}$, quien informó favorablemente, argumentando que Grana podía muy bien ser preferido, por su habilidad muy

\footnotetext{
${ }^{7}$ M. ${ }^{a}$ Luisa Tárraga, «El escultor vallisoletano Alfonso de Grana», en Estudios de Arte. Homenaje a Martín González. Universidad de Valladolid, 1995, 447-452.

${ }^{8}$ A.G.P. Sec. Reinado Carlos III, Leg. ${ }^{\circ} 503$.

${ }^{9}$ A.G.P. Sec. Reinado Fernando VI, antiguo Leg. ${ }^{\circ} 21$ de Casa.

${ }_{10}$ A.G.P. Sec. Reinado Fernando VI, antiguo Leg. 21 de Casa.
} 
señalada que tiene y porque, según dice, puede también sobrellevar el gasto que en esta manufactura ocurra, aludiendo el haber desempeñado con anterioridad algún trabajo similar, por encargo del marqués de Santa Cruz.

El Marqués de Villarias firmaba la orden de conformidad, para que se iniciase la restauración en estos términos: "Entreguense todas las estatuas de todas materias que él fuere pidiendo para componerlas de las que se maltrataron en el incendio del Real Palacio y otras si hubiere necesidad de reparo, tomando recibo siempre que se le fuesen entregando...», lo cual se trasmitía por el citado Duque al Secretario y Contralor de la Real Casa Juan Bautista Reparaz el 9 de febrero de $1747^{11}$.

La aceptación real, según se comprueba, fue inmediata y la razón básica opino que está en que la propuesta hecha por el escultor permitía la recuperación de la colección sin un gasto excesivo. Así, al menos, lo reflejan los documentos de archivo cuando señalan que el escultor, transcribo textualmente, «no pedía por ahora sueldo ni remuneración y se dice "parece que le induce solo la estimación que adquiere en su persona, y crédito de su facultad», aparte de que, se asegura, era acreedor a este encargo, por su «conocida habilidad y desempeño en quantas obras que de esta naturaleza se pusieron asu cuidado por el Marques de Santa Cruz, Mayordomo m. $^{\circ} r$ que fue de la Reyna nuestra Señora» ${ }^{2}$. Este detalle exige un comentario. En principio, no parece que haya plena conciencia de recuperar las obras por su valor, sino que la propuesta del artista, según los documentos, encubre el deseo de conseguir los honores y el prestigio que a otros se les otorga con más facilidad, mientras él no se consideró igualmente recompensado,. cuando confiesa al exponer sus quejas a Carlos III, en 1761, llevar prestando sus servicios a los reyes desde hacía más de 24 años. Por otra parte, es una ocupación que se promete duradera, en función del número de obras que tiene pendiente ante sus ojos para restaurar. Grana, además, es consciente de que otros escultores recién llegados a la Corte, como era el caso de Felipe de Castro o de Roberto Michel, disfrutaban de honores y sueldos de los que él carecía; incluso señala en una de sus quejas cómo Michel con sólo dos obras había conseguido nombramiento y sueldo de escultor de cámara, cuando el suyo, aun habiendo pagado la media annata y sus largos años de servicios, era sólo honorario.

También, a primera vista, se podría pensar en la necesidad de conseguir asegurarse un trabajo estable y duradero en la Corte que le permitiese el sustento personal y familiar, pero debemos desechar esta idea, ya que en estos años se trabaja intensamente en el taller de escultura para labrar toda la ornamentación del Palacio y a Grana siempre se le distribuyeron obras para esta decoración; luego, en principio, no era una necesidad de trabajo, sino más bien una ocupación que le permitiría conseguir independencia, prestigio y la consideración deseada. La restauración como medio de vida no se la planteará el escultor vallisoletano hasta bastantes años después, cuando, transcurridos diez años de dedicación a este trabajo, se decide no entregarle nuevas esculturas para restaurar.

En la aceptación de Fernando VI intuimos pudo converger la idea de conservar este Patrimonio, facilitándoselo el propio escultor, por el hecho de llevarlo a cabo con el menor coste posible. Además, disponemos de un escrito del rey, algunos meses más tarde, que vuelve a evidenciar el interés de Fernando VI en este sentido. El escrito está fechado, exactamente, el 30 de junio de 1747 en el Buen Retiro. En esta fecha hace escaso tiempo que Felipe de Castro acaba de llegar de Roma. Viene rodeado de un gran prestigio y goza de la consideración real. Acaba de ser nombrado escultor de cámara del rey y el escrito pone de manifiesto el deseo de Fernando VI de que su nuevo escultor de cámara restaure las esculturas deterioradas, tanto las

1 A.G.P. Sec. Reinado Fernando VI, antiguo Leg. ${ }^{\circ} 23$ Casa.

12 A.G.P. Sec. Reinado Fernando VI, antiguo Leg. ${ }^{\circ} 23$ Casa.

AEA, LXXVII, 2004, 305, pp. 21 a 33 
que se hallen en el interior del Palacio del Buen Retiro, como en los Jardines. No se cuestiona su costo; textualmente se dice: «Habiendo notado el Rey que entre las estatuas que se hallan colocadas en las habitaciones y en los Jardines de ese Sitio hay algunas que han padecido por incuria o por casualidad quiere S.M. que se compongan todas. A este fin me ha mandado -el que escribe es Montufar-dar orden a D. Felipe de Castro escultor de su Rl Persona para que venga a este Sitio y las reconozca y luego me diga cuales y cuantas son las que necesitan alguna composición.

V.S.disponga que se le franquen todas las piezas en que haya estatuas o otras piezas de escultura para que haga los reconocimientos que el Rey quiere que se executen. Pero para que pueda sacar del Sitio cualquier estatua o pieza será preciso que presente a V.S. una orden mía... a donde deba anotar de la extracción por medio del recibo que deban firmar el mismo D. Felipe de Castro...» ${ }^{13}$. La noticia, aparte de corroborar el interés y la iniciativa de la restauración escultórica bajo el reinado de un monarca nacido y criado en España, Fernando VI, anticipándose así a su hermanastro Carlos III en la conservación del Patrimonio, va a tener posteriores consecuencias, pues va a suponer el enfrentamiento o, al menos, la disparidad de criterios que en el campo de la restauración se plantea entre dos escultores de cámara :Alfonso de Grana y Felipe de Castro, enfrentamiento que nos desvelan los documentos ocho años después.

¿Cuántas esculturas se habían restaurado hasta entonces? Alfonso de Grana había iniciado su trabajo en 1747, tomando de la furriera de S.M., que entonces estaba en el Palacio Arzobispal, cuatro estatuas de distintas materias que dice el propio escultor las llevó a su casa -en la calle de la Manzana - para irlas componiendo por no haberle dado entonces casa ni obrador; pero Grana decidió, teniendo en cuenta el volumen de obra a restaurar, construirse un obrador nuevo, puesto que, como el mismo artista manifiesta, el volumen de piezas y el tamaño de los mármoles exigía de un mejor espacio. Aparte de ello precisó de herramientas o instrumentos que especifica como: «Bancos Grandes y Banquillos medianos medianos y pequeños y Prensas y tornillos todos de madera con sus husillos y un Bastidor Grande con cuatro pies, un Torno Grande con sus usillos de Yerro y sus Birolas de lo mismo, y unos Yerros, el uno en forma de tenedor, unas Angarillas Grandes de Madera con quatro pies, y unos instrumentos pequeños de madera con su Bastidor y sus Taladros de ballesta, y un Instrumento que se llama Trepan con su rueda de plomp y sus virolas de Yerro, que sirve para meter los taladros en él y taladrar la Piedra; un Barrilete de Yerro, diferentes formones Grandes y Medianos; unas barrenas muy largas y otras pequeñas...», gubias, escofinas, cinceles, punteros, uñetas, gradinas y «marcelinas en forma de martillo... y otras muchas menudencias que no pongo» ${ }^{14}$. Junto con el obrador, el artista vallisoletano había invertido para la restauración la suma total de 5.562 rs. ${ }^{15}$.

Conforme concluía las restauración de las obras Grana iba entregándolas y recogía otras nuevas. Tenemos constancia documental de que, entre otras, se le entregaron las siguientes: $U n$ Ecce Homo de medio cuerpo de Barro cocido, tamaño natural, con su peana negra de Madera fina hecho del Cavallero Moreli. Un Niño Jesús de Resurrección en marfil de una vara de alto poco mas inclusa la peana que tiene de peral., Una Nra Señora de piedra de alabastro de Trapani de Bulto con su peana de la misma piedra, de poco mas de una vara de alto. Una Cabeza Antigua de mármol de Carrara de un Emperador, tamaño del Natural consu peana del mismo Mármol. Una estatua griega de un joven desnudo de mármol y un retrato en mármol de cuerpo entero de Carlos $V^{16}$. ¿Cuáles eran los criterios que Grana aplicaba en sus restauraciones? Es algo que los propios documentos y hasta el propio Grana se encarga de desvelar-

\footnotetext{
13 A.G.P. Secc. Buen Retiro, C. ${ }^{\mathrm{a}} 11746 / 14$.

14 A.G.P. Sec. Reinado Carlos III, Leg. ${ }^{\circ} 503$.

15 A.G.P. Secc. Personal, C. ${ }^{a} 477 / 39,22$ febrero de 1761.

16 A.G.P. Sec. Personal, C. ${ }^{a}$ 477/39, año 1761 y Sec. Reinado Carlos III, Leg. 503.
}

AEA, LXXVII, 2004, 305, pp. 21 a 33 
nos. Por su interés, me permito transcribirlo textualmente. Dice Grana: «Primeramente compuse un Eccehomo del natural de medio Cuerpo, hasta el Pañete, que tiene sus brazos, y es de barro cocido hecho del Caballero Morely, y ha sido del Oratorio de Palacio: cuya hechura estaba toda hecha pedazos, desde la Cabeza y rostro hasta el Pañete, que por haber estado más expuesto al riesgo, le faltaban muchos pedazos grandes, como es todo el brazo derecho desde el molledo, hasta el hombro derecho, en donde le he echado diferentes Piezas grandes de la misma materia, echos de barro, y cozidos, y toda la mano de dicho brazo, la eché toda nueva hasta el principio del Brazo, y de la misma materia y la mano izquierda era nueva hasta el nacimiento de los dedos: Toda la cabeza y rostro estaban desbaratados, y eché las Piezas que le faltaban, y lo demás lo pegué: Previniendo que además de pegarlo les hice sus taladros, y puse sus espigas de yerro para su mayor seguridad y permanencia; de manera que he tenido que hacer treinta y siete piezas nuevas, que le faltaban sin las de las manos, además de las Pegaduras, asiento de la caveza, y todo el desnudo, y ropage.

$Y$ se hace presente que dicha hechura es de barro de Alcalá, y estaba antes dado su color a todo el cuerpo, imitando al expresado varro y ahora se ha hecho lo mismo, dándole su color imitando a lo que antes había tenido; Y la Peana es de madera que está toda quebrada, y la faltaban Piezas, y se echaron nuevas y quatro Piezas en los ángulos para la seguridad de lo moldado de la peana con una espiga gorda de madera, y encolarlo todo sobre la Peana, y que S.M. se mantenga en ella firme, y no se quiebre nada del cuerpo, y a la dicha Peana, se la pintó de negro sobre sus yesos, y se la barnizó» ${ }^{17}$.

Continúa Grana exponiendo: "It. he compuesto un niño de Resurrección de marfil, de una vara de alto poco más inclusa la Peana, que es de madera de Peral, el que tenía despegados los brazos y los pies quebrados a los que ha sido necesario pegar y para mayor seguridad los he taladrado para ponerlos unas Espigas de yerro, y al pelo se le dió su color y se limpió, como lo había tenido, y la Peana estaba bien tratada, y se la compuse, y di de negro».

Prosigue diciendo: «It. una Nra Señora de Trapana de Piedra de Alabastro (fig. 3) de una vara de alto poco menos inclusa en dicha medida la Peana la que es de la misma materia, con su niño en el Brazo izquierdo; cuia hechura estaba bien maltratada, y a la imagen le faltaba un dedo, y al niño otro en un pie, y en el ropaje tenía algunas rozaduras, y al Plinto sobre que está la Ymagen la he echado quatro Piezas nuevas, que le faltaban de piedra alabastro, y a la imagen hice la punta del pie izquierdo de lo mismo, y al manto le faltaba una pieza, y se la hice nueva y a todo el ropaje por el forro se le pintó de azul, que antes había tenido, y al niño, de color encarnado carmesí, y se ha barnizado, y a todo el ropaje se le compusieron las flores, y a la peana el escudo, que tiene en medio; se hizo lo mismo en los ojitos y caules de talla; y a la Ymagen he puesto dos Espigas nuevas de madera para seguridad que antes no había tenido más que una muy delgada, por cuya razón estaba despegada de la peana ${ }^{18}$.

It. he compuesto una Caveza con su Pescuezo hasta más abajo de la Clavícula, que está puesta sobre un zócalo y está sobre su peana redonda, toda la cabeza, y peana es de mármol de Carrara, y de media vara y tres dedos de alto, poco más o menos, la que estaba toda hecha

17 A.G.P. Secc. Personal, C. a 477/39, 1755- 2 de abril.

Este Ecce Homo figura inventariado en la testamentaría del rey Carlos II, concretamente, en el Oratorio del Despacho de la Torre con el $\mathrm{n}^{\circ} 40$ y se inventarió posteriomente, tras el incendio, entre aquellas esculturas que estaban almacenadas en las Casas Arzobispales con el n. ${ }^{\circ} 15$, entre las Alhajas antiguas,indicándose que estaba «muy maltratado»,y tasándose, supuestamente por razón de su estado, en sólo 400 rs. (A.G.P., Sec. Reinado de Felipe V, Leg. 209). Desconocemos su actual paradero.

18 La imagen se conserva actualmernte en el Palacio Real de Madrid identificándose los colores del manto a los que alude Grana, así como algunos otros detalles de su restauración, entre ellos el escudo de la peana. Una imagen similar a ésta se conserva en el Museo Arqueológico Nacional y fue reproducida por Angela Franco en su estudio «La Madonna di Trapani y su repercusión en España»

AEA, LXXVII, 2004, 305, pp. 21 a 33 
pedazos, y la he hechado todas las piezas que le faltaban y entre ellas le he hecho las dos orejas nuevas, las que además de pegar se le han hecho sus taladros, y echado sus espigas de yerro, y las narices lo mismo, no los he contado porque el Artifice que lo apreciase lo podrá hazer, por se conocen por las Pegaduras...».

Acaba diciendo Grana «no pongo en esta memoria lo que S.M. me ha de mandar dar por todo el trabajo, que he tenido en dicha composición dejándolo al juicio que hiciere el artífice, que lo tasase...» ${ }^{19}$.

Después de leer tan pormenorizado trabajo, descrito por el propio escultor, cabe preguntarse si tal y como dejó restaurado el Ecce Homo ¿Moreli hubiese podido reconocer su obra? El escultor vallisoletano en sus intervenciones, con el afán de recuperar las esculturas, al rehacer todas aquellas partes perdidas ¿conseguía devolvernos el original, destruía la obra original o se trataba de hacer arte sobre arte?

En el caso de la estatua de Carlos V en mármol,de cuerpo entero, obra de los Leoni, (fig. 4), una de las que habían permanecido en el Alcázar, concretamente en la llamada Bóveda de Ticiano, hoy en el Museo del Prado, no sabemos con precisión cuáles eran los desperfectos que tenía. Si tenemos en cuenta el estado de la estatua actualmente, hay que intuir que presentaría desperfectos idénticos a los que hoy apreciamos en ella: pérdida de los dedos de la mano derecha; pérdida de parte de la espada que con esta misma mano sostenía; aquellos otros deterioros que podemos observar en el manto, en la figura del águila o en el pie izquierdo. Grana la restauró, pero criterios más puristas en cuanto a restauración debieron proceder a desprender de la obra todas las restauraciones que desmerecían del original, para posteriormente proceder a restaurarla, aunque con el mismo éxito, porque otros restauradores siglos después debieron preferir dejarla en su estado de mutilación. Curiosamente, hemos conseguido averiguar que años después, exactamente en 1773, fue Felipe de Castro quien se encaragará de restaurarla.

Los criterios de restauración que practicaba Alfonso de Grana nada tenían que ver con los criterios y técnicas de Olivieri y Castro a los que éste pudo haber conocido directamente durante su estancia en Italia.

Se decide que las piezas que Grana entrega concluidas debían ser examinadas y tasadas, previamente a su pago, por otros escultores. Para ello serán los elegidos el escultor principal del rey y el de cámara: Olivieri y Castro; el uno de origen italiano, el otro formado en Italia. Castro, al valorar el trabajo que el escultor vallisoletano había realizado en las ya referidas cuatro esculturas, se lamentará de no haberlas podido examinar previamente a su restauración; de cualquier forma,para él la compostura del Ecce Homo merecía 500 rs., la del niño en marfil 100, la Virgen 300 y la cabeza de mármol otros 300 y exige que para poder él cumplir debidamente al real servicio que «se hace forzoso que antes que se compongan las hechuras, las vea y reconozca, para con pleno conocimiento executar las tasas y ver cuando las entreguen si están bien ejecutadas las composturas, y cuanto merecen según ellas, porque de otra forma no se logrará el intento del mejor acierto...» ${ }^{20}$.

El 4 de marzo de 1756 en presencia de Olivieri y de Castro se le entregaron a Alfonso de Grana dos nuevas estatuas antiguas en mármol blanco. Al finalizar el año -8 de diciembre de 1756- el Duque de Alba pedía que Olivieri y Castro informasen si la obra de restauración que Grana hacía en la colección era «buena o perjudicial» para las estatuas y que ambos expresasen su parecer. Felipe de Castro comunica se encuentra enfermo ya hace más de un mes y Olivieri decide que, cuando Castro esté bueno, irán los dos a ver el trabajo hecho por Grana ${ }^{21}$.

\footnotetext{
19 A.G.P., Secc. Personal, C. ${ }^{a} 477 / 39,24$ abril 1755.

20 A.G.P., Sec. Personal, C. ${ }^{\text {a }} 477 / 39,29$ abril 1755.

${ }_{21}$ A.G.P., Sec. Personal, C. ${ }^{\circ}$ 477/39, 11 diciembre 1756.
} 
El parecer de Castro está fechado el 16 de febrero de 1757. Comunica Castro que junto con Olivieri han estado en las dos estatuas que le habían entregado: la una griega de un joven desnudo, y la otra el retrato de Carlos V de cuerpo entero, las dos de mármol. Informa el artista gallego que Grana tenía «hechas a medio concluir todas las piezas, con sus acopladuras y señala «esto es en acuanto a la primera parte, por lo que toca a la segunda, su obra no corresponde al carácter de las dos Estatuas, ni a la buena restauración, que en Roma se practi$c a$, y aunque es verdad que Grana en esta composición puso un trabajo excesivo, por falta de inteligencia, porque con menos trabajo, y más saber se hubiera conseguido mejor el fin del Restauro», y aquí aparece expresado el propio parecer del artista gallego, quien dice que: «... el fin del Restauro, es que lo nuevo sea del mismo carácter y elegancia de lo viejo, y no desdiga a lo menos de él en lo que sea posible, por lo que soy del parecer no se le deban entregar más estatuas para restaurar, de cuyo dictamen ha sido también Olivieri, según explicó al tiempo del reconocimiento, y que formaría y dirigiría su respuesta a V.S. en papel aparte...» ${ }^{22}$. Ambos profesores tasaron el trabajo, pero Olivieri llegó a decir que él no respondería de estas composiciones, si más estatuas se le entregan. Grana insistía en que se le diesen nuevas estatuas para seguir reparándolas, y, asímismo, pedía se le pagase el obrador que él había construido y los instrumentos con los que había estado realizando su trabajo, si bien por parte de la administración se alegaba que a ningún Oficial de mano se le pagaba de cuenta del rey ni el obrador ni los instrumentos de trabajo. Exactamente era 2 de marzo de 1759.

La disparidad en la tasación hecha por los escultores del rey a su trabajo también suscitó la consiguiente protesta del artista vallisoletano, quien exponía los perjuicios que todo le ocasionaba, desde la tasación desigual: Castro en 6.000 rs. y el escultor principal «con más conocimiento, dice, lo taso en nueve mil rs. de v. ${ }^{\circ}$.» Grana acudió al Duque de Alba para que le entregasen nuevas estatuas, pero mando S. Ex. ${ }^{a}$ cesase en ello, y dice textualmente el documento «y viendo el Supte el perjuicio tan grave que de ella se le seguía por no tener que trabajar, y que por el Rl. Decreto anterior de S.M. tenía mandado se le bonificase al Supte todos los gastos que hubiese tenido para esta basta manifactura hizo presente al Duque de Alba que era necesario se le pagasen todo, como fue el haber hecho un obrador nuevo a su costa y las demás prevenciones e instrumentos y gastos necesarios para continuar en ello; por ser trabajo largo de algunos años no quiso entonces, dice Grana, hacer presente estos gastos por no deteriorar el Rl Erario y contentarse con lo que se le iba dando por su trabajo. Y pide y suplica se le paguen todos los gastos que hizo tal y como había mandado Fernando VI», quien precisamente ya en estas fechas había fallecido. También expone el perjuicio ocasionado por la disparidad de criterios entre Olivieri y Castro al tasar su trabajo, sin que él hubiese tenido ocasión de haber nombrado otros dos tasadores por su parte. Grana añade que hacía 24 años que había dedicado al servicio de Felipe V y su esposa, así como a Fernando VI y que, de haber continuado en la composición de las esculturas, no hubiera pedido nada por estos gastos, los cuales hizo presente al Duque de Alba, que previos los informes pertinentes le mandó abonar lo que el artista vallisoletano reclamaba. Castro y Olivieri hubieron de tasar nuevamente el trabajo de las seis estatuas restauradas por Grana, tras la insistencia y quejas de este escultor. Ambos se afirmaron en la valoración ya hecha e incluso como al volverlas a tasar no encontraban «la cabeza antigua de marmol de Carrara de un Emperador». Castro dice que hubo que recurrir al Inventario General hecho por Grana y firmado el 21 de febrero de 1747. El escultor gallego demuestra que Grana había valorado las cuatro primeras piezas restauradas en el citado inventario, «comprendido hechuras y materiales en $2.700 \mathrm{rs}$., cuando el pedazo de marfil del Niño Jesus nos parece que esto solo valdra el dinero en que se aprecio las cuatro...», de-

${ }^{22}$ A.G.P., Sec.Personal, C. ${ }^{\text {a }}$ 477/39 16 febrero 1757.

$A E A$, LXXVII, 2004, 305, pp. 21 a 33 
mostrando así que su tasación por la restauración de las cuatro «fue muy arreglada, y hecha con todo conocimiento y inteligencia» y afirmándose en la valoración ya hecha de las otras dos en 6.000 rs. Tanto Olivieri como Castro aseguran que,efectivamente, era preciso un obrador e instrumentos nuevos para una obra de tanta importancia y tan grande y que Grana pudo haber necesitado todo lo que decía había comprado y hecho, pero opinan que « como estas son obras, unas hechas por albañiles, y otras por carpinteros y otras por herreros, no las podemos apreciar, por cuanto sólo los mesmos artesanos las pueden valuar, por esta razón no habemos hecho este reconocimiento». La nueva valoración hecha por Castro y Olivieri aparece fechada en 14 de febrero de 1761.

El obrador fue tasado por el aparejador principal de obras reales, Antonio Valenciano, y por los arquitectos nombrados por el Consejo de Castilla. Grana no dejó de seguir presentando sus quejas a Carlos III,quien el 9 de julio de 1761 acabó por condescender a sus continuas reclamaciones, pagándosele como gasto extraordinario por la Tesorería mayor de Guerra el 17 de julio de 1761 la suma de 4.654 rs. ${ }^{23}$, pues Grana convino en quedarse con el obrador en los 908 rs., en que había sido valorado por el aparejador principal, mientras todos los instrumentos quedaban a disposición del rey.

Paradójicamente, cuando se da por zanjada esta restauración escultórica, es Carlos III quien reina en España.

Grana se vio obligado a abandonar este trabajo por los informes de Castro y Olivieri, que evidencian criterios encontrados con el artista vallisoletano en cuanto a la forma en que debe practicarse la labor de restauración.

Las razones convencieron a un monarca como Carlos III, quien, precisamente, había asumido desde tiempo atrás, siendo rey de Nápoles, la recuperación de tantas y tan bellas obras de la Antigüedad.

Esta paralización, sin embargo, no fue definitiva, ya que años más tarde, exactamente en 1773, Felipe de Castro emprenderá de nuevo la tarea de recuperar la colección El trabajo se prolongó a lo largo del XVIII e incluso se continuará en el siglo XIX, cuando las esculturas pasaron al Real Museo o actual Museo del Prado.

La monarquía española empleó crecidas sumas en la restauración de la colección, siendo los mejores escultores al servicio de los reyes los que estuvieron encargados de tan importante misión.

\footnotetext{
${ }^{23}$ A.G.P., Sec. Reinado de Carlos III, Leg. ${ }^{\circ} 87$ y A.G. Simancas Tesoro. Inv. 25 , Leg. 5 fol. 42 vt. $^{\circ}$
} 